\title{
HOXB7-S3 inhibits the proliferation and invasion of MCF-7 human breast cancer cells
}

\author{
RUI MA ${ }^{1}$, DAN ZHANG ${ }^{1}$, PENG-CHAO HU ${ }^{2}$, QUN LI $^{3}$ and CONG-YAO LIN ${ }^{1}$ \\ ${ }^{1}$ Department of Oncology, Zhongnan Hospital of Wuhan University, Hubei Cancer Clinical Study Center, \\ Key Laboratory of Tumor Biological Behavior of Hubei; ${ }^{2}$ Department of Pathology and Pathophysiology, \\ Research Center of Food and Drug Evaluation, School of Basic Medical Sciences, Wuhan University; \\ ${ }^{3}$ Renmin Hospital of Wuhan University, The First College of Clinical Medicine of Wuhan University, \\ Wuhan, Hubei 430071, P.R. China
}

Received September 13, 2014; Accepted June 3, 2015

DOI: $10.3892 / \mathrm{mmr} .2015 .4009$

\begin{abstract}
Homeobox B7 (HOXB7) has been found to be overexpressed in numerous types of human cancer. However, the role of HOXB7 in breast cancer remains to be elucidated. The aim of the present study was to investigate the effects of HOXB7 on the proliferation and invasion of breast cancer cells. Initially, reverse transcription quantitative polymerase chain reaction and western blotting were respectively employed to detect the mRNA and protein expression levels of the HOXB7 gene in the MDA-MB-231 and MCF-7 human breast cancer cell lines. Subsequently, small interfering RNAs designed to interfere with the expression of HOXB7 were used to knockdown the expression of HOXB7 in the MCF-7 cell line, the effects of which on cell proliferation, the apoptotic rate and invasion capacity were measured using a Cell Counting kit- 8 assay, flow cytometry and transwell chambers, respectively. The results demonstrated that HOXB7 mRNA and protein were all overexpressed in MDA-MB-231 and MCF-7 breast cancer cell lines. Furthermore, HOXB7-S3 effectively inhibited the proliferation and invasion of MCF-7 breast cancer cells. In conclusion, these results demonstrated that HOXB7 may be a potential therapeutic target in human breast cancer.
\end{abstract}

\section{Introduction}

Breast cancer is the most frequently diagnosed cancer and the leading cause of cancer mortality among females, accounting for $23 \%$ of total cancer cases and $14 \%$ of cancer mortalities (1).

Correspondence to: Professor Cong-Yao Lin, Department of Oncology, Zhongnan Hospital of Wuhan University, Hubei Cancer Clinical Study Center, Key Laboratory of Tumor Biological Behavior of Hubei, 169 Donghu Road, Wuchang, Wuhan, Hubei 430071, P.R. China

E-mail: lincongyy@163.com

Key words: homeobox B7, breast cancer, proliferation, apoptosis, invasion
Breast cancer has the best prognosis when detected at early stages. However, patients diagnosed with advanced breast cancer or metastatic breast cancer have a poor prognosis. Therefore, in order to improve the overall survival rate of patients with breast cancer, it is of importance to investigate factors that could promote the proliferation, invasion and metastasis of human breast cancer cells.

A variety of genes are involved in the development of breast cancer, including BRCA1, BRCA2, p53 (2) and c-erbB-2 (3). Previously, it has also been reported that HOX genes are widely correlated with various types of cancer (4-6).

The homeobox (HOX) subgroup of the HOX supergene family encompasses 39 genes located in four contiguous clusters (HOXA, HOXB, HOXC and HOXD) (7). HOX genes containing a 183-bp DNA sequence coding for a 61-amino-acid domain defined as the homeodomain (HD) (8), which is responsible for the recognition and binding of sequence-specific DNA motifs (9), are transcription factors that are important in anterior-posterior body axis patterning during normal embryonic development (7). However, aberrant expression of HOX genes has been demonstrated in different tumor types, including leukemia (10), ovarian carcinoma (11) and pancreatic cancer (12), suggesting that HOX genes are important in various types of tumor.

HOXB7 is a newly identified member of the HOX gene family. It is highly expressed in embryonic tissues and is limited to specific tissues of the embryo during the late trimester of pregnancy but is not detected in the majority of terminally differentiated adult tissues under normal conditions. As a transcription factor, HOXB7 is also important in embryogenesis and tissue differentiation. However, deregulation of HOXB7 has been observed in esophageal squamous cell carcinoma, oral cancer, ovarian carcinoma and breast cancer (13-16). In addition, it has been reported that increased expression of HOXB7 was closely associated with tumor cell proliferation, invasion and metastasis $(7,14,17)$.

However, the role of HOXB7 in breast cancer has yet to be characterized. In the current study, the mRNA and protein expression levels of HOXB7 in breast cancer cells were investigated and the effect of HOXB7-siRNA on the proliferation, apoptosis and invasion capacity of breast cancer was 
determined using a CCK-8 assay, flow cytometry (FCM) and transwell chambers. It was hypothesized that HOXB7 siRNA inhibits the proliferation and invasion of breast cancer cells and that HOXB7 may have therapeutic potential in breast cancer.

\section{Materials and methods}

Main reagents and instruments. Fetal bovine serum (FBS), RPMI-1640 medium, penicillin, streptomycin, phosphate-buffered saline (PBS; used as a solvent) and pancreatic enzymes were purchased from HyClone Laboratories, Inc. (Logan, UT, USA). The primers for HOXB7 and GAPDH, rabbit monoclonal anti-human HOXB7 antibody, Lipofectamine 2000 and Lipofectamine ${ }^{\mathrm{TM}}$ RNAi MAX transfection reagents were obtained from Invitrogen Life Technologies (Carlsbad, CA, USA). The RevertAid ${ }^{\mathrm{TM}}$ First Strand cDNA Synthesis kit was purchased from Fermentas (Vilnius, Lithuania). The mouse polyclonal anti-human GAPDH antibody was obtained from Tianjin Sungene Biotech Co., Ltd. (Tianjin, China), siRNA was obtained from Shanghai Genepharma Co., Ltd., (Shanghai, China), the Cell Counting kit-8 (CCK-8) was purchased from Beyotime Institute of Biotechnology (Wuhan, China), Transwell plates were obtained from Corning Inc. (Corning, NY, USA), Matrigel was purchased from BD Biosciences (San Jose, CA, USA) and the Annexin-V-EGFP/propidium iodide (PI) Apoptosis Detection kit was obtained from EnoGene Biotech Co., Ltd. (Nanjing, China).

Cell culture and treatments. MDA-MB-231 and MCF-7 human breast cancer cell lines were purchased from the China Center for Type Culture Collection (Wuhan, China). The cells were cultured in RPMI-1640 medium containing 10\% FBS, $1 \%$ penicillin/streptomycin $(100 \mathrm{U} / \mathrm{ml}$ penicillin- $\mathrm{G}$ and $100 \mu \mathrm{g} / \mathrm{ml}$ streptomycin) at $37^{\circ} \mathrm{C}$ in a humidified incubator that was supplemented with $5 \% \mathrm{CO}_{2}$. The cells were then passaged at $80-90 \%$ confluence and digested with $0.25 \%$ trypsin.

$R N A$ extraction and reverse transcription quantitative polymerase chain reaction ( $R T-q P C R)$. Total RNA was isolated from MDA-MB-231 and MCF-7 breast cancer cells using TRIzol reagent (Invitrogen Life Technologies). Total RNA $(1.0 \mu \mathrm{g})$ was transcribed into complementary DNA (cDNA) using the RevertAid ${ }^{\mathrm{TM}}$ First Strand cDNA Synthesis kit according to the manufacturer's instructions. The RT reaction was performed at $25^{\circ} \mathrm{C}$ for $10 \mathrm{~min}, 42^{\circ} \mathrm{C}$ for $60 \mathrm{~min}$ and $70^{\circ} \mathrm{C}$ for $10 \mathrm{~min}$. The mRNA levels were analyzed by RT-qPCR using the SYBR Premix Ex Taq System (Clontech Laboratories, Inc., Mountain View, CA, USA). The following primers were used: GAPDH, forward 5'-AATCCCATCACCATCTTCCAG-3' and reverse 5'-GAGCCCCAGCCTTCTCCAT-3' (118 bp); HOXB7, forward 5'-TACCCCTGGATGCGAAGCTC-3' and reverse 5'-AATCTTGATCTGTCTTTCCGTGA-3' (171 bp). The reaction mixture, including $10.0 \mu \mathrm{l}$ of $2 \mathrm{X}$ All-in-One ${ }^{\mathrm{TM}}$ qPCR Master mix (GeneCopoeia, Rockville, MD, USA; AOPR-1200), $0.4 \mu 1$ of forward primer, $0.4 \mu 1$ of reverse primer, $5 \mu \mathrm{l}$ of cDNA (10X dilution) and $4.2 \mu \mathrm{l}$ of $\mathrm{ddH}_{2} \mathrm{O}$, was incubated at $95^{\circ} \mathrm{C}$ for $10 \mathrm{sec}, 60^{\circ} \mathrm{C}$ for $20 \mathrm{sec}$ and $72^{\circ} \mathrm{C}$ for $20 \mathrm{sec}$ for 40 cycles. The mRNA level of each sample was measured by the $2^{-\Delta \Delta C T}$ method (18). In addition, qPCR (Applied Biosystems StepOnePlus ${ }^{\mathrm{TM}}$ Real-Time PCR System;
Applied Biosystems, Foster City, CA, USA) was performed three times independently.

Western blotting. Cells were extracted using radioimmunoprecipitation assay protein lysis buffer and the level of protein expression was measured using the bicinchoninic acid assay protein assay kit (Thermo Fisher Scientific, Inc., Wuhan, China). Total protein ( $40 \mu \mathrm{g}$ ) was loaded and run on a $12.5 \%$ SDS-polyacrylamide gradient gel and 4\% SDS-polyacrylamide stacking gel. Subsequently, protein was transferred onto nitrocellulose filter membranes for $1.5 \mathrm{~h}$ and then incubated with $5 \%$ non-fat milk at room temperature for $2 \mathrm{~h}$ to block nonspecific binding. This was then washed three times with Tris-buffered saline with Tween 20 (TBST; 5 min each time) and then treated with rabbit monoclonal anti-human HOXB7 antibody (1:400; Invitrogen Life Technologies; cat. no. 40-2000) and mouse polyclonal anti-human GAPDH antibody (1:10,000; Tianjin Sungene Biotech Co., Ltd.; cat. no. KM9002) overnight at $4^{\circ} \mathrm{C}$ with continuous agitation. Subsequently, membranes were combined with corresponding secondary antibody, goat anti-rabbit immunoglobulin G (IgG)/horseradish peroxidase (HRP; 1:10,000 dilution; MR Biotech, Co., Ltd., Shanghai, China) and goat anti-mouse IgG/HRP; (1:10,000 dilution; MR Biotech, Co., Ltd.) at $37^{\circ} \mathrm{C}$ for $1 \mathrm{~h}$ after washing three times in TBST (15 min each time). Finally, the protein levels were analyzed using an enhanced chemiluminescence kit (Biossci Biotechnology Co., Ltd., Wuhan, China) according to the manufacturer's instructions. Gray scale images were determined by Quantity One 4.62 software (Bio-Rad Laboratories, Inc., Hercules, CA, USA) and analyzed using GraphPad Prism 5 software (GraphPad Software Inc., La Jolla, CA, USA). The optical density for target protein was shown as a proportion of GAPDH optical density. The experiments were replicated three times.

Synthesis of HOXB7-siRNA. Three sequences of siRNA oligonucleotides targeting HOXB7 synthesized by Shanghai Genepharma Co., Ltd. were identified and matched with the following HOXB7 cDNA sequences obtained from GenBank through a BLAST search (http://blast.ncbi.nlm.nih. gov/Blast.cgi): Sequence 1 (S1), sense (HOXB7-homo-462) 5'-GAGAGUAACUUCCGGAUCUTT-3'; sequence 2 (S2), sense (HOXB7-homo-633): 5'-CGGAAA GACAGAUCAAGAUTT-3'; sequence of siRNA3, (S3), sense (HOXB7-homo-1083): 5'-GCUAUUGUA AGGUCUUUGUTT-3'. The siRNA sequence that exhibited the highest interfering efficiency was selected to continue the study. By contrast, one sequence of negative control siRNA (Sn) was synthesized as: 5'-UUCUCCGAACGUGUCACGUTT-3' (sense).

siRNA transfection. The MCF-7 breast cancer cells cultured as described were divided into the following five groups: Con-B group, blank control group; Sn group, negative control siRNA; S1 group, S1 transfection group; S2 group, S2 transfection group and S3 group, S3 transfection group. Cells were seeded on 6-well plates at a density of $1 \times 10^{6}$ cells/well $24 \mathrm{~h}$ prior to transfection. When $80-90 \%$ confluence was reached, HOXB7-siRNA or negative control siRNA were transfected into MCF-7 cells at three different concentrations $(0.1,0.2$ and 
$0.4 \mu \mathrm{M}$, respectively) using Lipofectamine 2000 (Invitrogen Life Technologies) in RPMI-1640 medium. Fluorescence, which was detected under a fluorescence microscope (VHB100F; Olympus Corporation, Shanghai, China) after transfection for 4-6 h, was used to optimize the condition of transfection.

Detection of interference efficiency by RT-qPCR and western blotting. Following transfection with HOXB7-siRNA for 48 and $72 \mathrm{~h}$, five groups of MCF-7 cells were harvested to detect the mRNA and protein expression levels of HOXB7 by RT-qPCR and western blotting as described above, respectively. Interference efficiencies were calculated as follows: Interference efficiency $=(\mathrm{mRNA}$ expression of HOXB7 in the control group - mRNA expression of HOXB7 in the treatment group) / mRNA expression of HOXB7 in the control group $\mathrm{x} 100 \%$. Each experiment was repeated three times. Cells transfected with siRNA3 had the lowest expression levels of HOXB7 mRNA and protein and, therefore, S3 was used in the following experiments.

CCK-8 cell proliferation assay. According to the manufacturer's instructions for the CCK- 8 assay, the three groups of MCF-7 cells, including the Con-B group (blank control group), $\mathrm{Sn}$ group (negative control siRNA) and S3 group (siRNA3 transfection group) were collected at the exponential phase and inoculated onto a 96 -well plate at a density of $5 \times 10^{3}$ cells/well. Following inoculation for $24,48,72$ or $96 \mathrm{~h}$, each well was replaced with $100 \mu 1$ RPMI-1640 supplemented with $10 \%$ FBS, $1 \%$ penicillin/streptomycin and $10 \mu \mathrm{lCCK}$. Subsequently, the cells were incubated at $37^{\circ} \mathrm{C}$ away from light for $4 \mathrm{~h}$. The absorbance was then measured at $450 \mathrm{~nm}$ for each well using a microplate reader (ELx808 ${ }^{\mathrm{TM}}$; BioTek Instruments, Inc., Winooski, VT, USA). Cell viability was calculated using the following formula: Cell viability $(\%)=($ Absorbance in treated sample / Absorbance in control) x 100\%. Three independent experiments were performed with triplicate wells.

Flow cytometric analysis. Following the transfection of MCF-7 cells with HOXB7-S3 and Sn for $48 \mathrm{~h}, 1 \times 10^{6}$ cells were collected and then resuspended in $500 \mu \mathrm{l}$ binding buffer containing $5 \mu \mathrm{l}$ Annexin V-EGFP conjugated antibody and $5 \mu \mathrm{l}$ PI for exactly $5 \mathrm{~min}$ in the dark at room temperature. Cells were transferred into flow test tubes within $1 \mathrm{~h}$ and then detected on a BD FACSCalibur flow cytometer (Becton-Dickinson, San Jose, CA, USA). The data were analyzed using FlowJo software version 6.0 (Tree Star, Inc., Ashland, OR, USA).

Cell invasion assay. Transwell membranes were purchased from Corning Inc. Matrigel $(100 \mu \mathrm{l})$, which was diluted in serum-free RPMI-1640 medium following thawing at $4^{\circ} \mathrm{C}$ overnight, was placed into the upper chamber of a 24-well transwell and the transwell was incubated at $37^{\circ} \mathrm{C}$ for at least 4-5 h for gelling. Three groups of MCF-7 cells grouped as described above with a given concentration of $5 \times 10^{3}$ cells $/ \mathrm{ml}$ were prepared, $100 \mu \mathrm{l}$ of which was added to the upper chamber at $37^{\circ} \mathrm{C}$. At 24 and $48 \mathrm{~h}$ post-incubation, the cells were fixed with formaldehyde, stained and counted under a microscope (37XB; Zhonghen Instrument, Co., Ltd.,

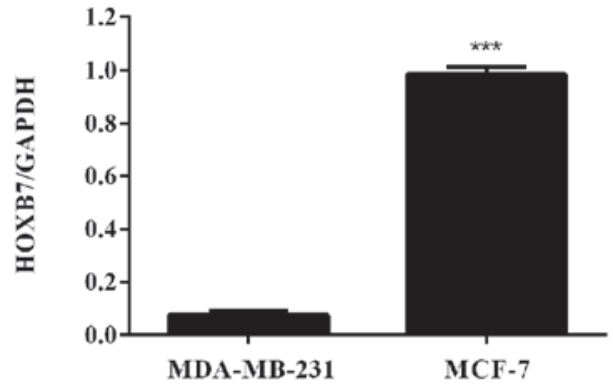

Figure 1. mRNA expression level of HOXB7 in two breast cancer cell lines assessed by reverse transcription quantitative polymerase chain reaction. HOXB7 mRNA was overexpressed in MDA-MB-231 and MCF-7 breast cancer cell lines and the expression level in MCF-7 breast cancer cells was significantly higher compared with that in MDA-MB-231 breast cancer cells $\left({ }^{* * *} \mathrm{P}<0.001\right)$. HOXB7, homeobox B7.

Shanghai, China). The invasion activity of the carcinoma cells was characterized with the average transmembrane cell numbers. Each experiment was repeated three times.

Statistical analysis. Each experiment was repeated three times. All data are expressed as the mean \pm standard deviation and undertaken using the statistical software SPSS 18.0 (SPSS, Inc., Chicago, IL, USA). Comparisons were made using an independent samples t-test. $\mathrm{P}<0.05$ was considered to indicate a statistically significant difference $\left({ }^{*} \mathrm{P}<0.05,{ }^{* *} \mathrm{P}<0.01\right.$ and $\left.{ }^{* * *} \mathrm{P}<0.001\right)$

\section{Results}

HOXB7 mRNA is overexpressed in two breast cancer cells. To detect the mRNA expression level of HOXB7 in breast cancer cells, RT-qPCR was used in two human breast cancer cell lines, including MDA-MB-231 and MCF-7 cells. The results of the RT-qPCR revealed that HOXB7 mRNA was overexpressed in MDA-MB-231 and MCF-7 breast cancer cell lines and the expression level in MCF-7 breast cancer cells was significantly higher compared with that in MDA-231 breast cancer cells $\left({ }^{* * *} \mathrm{P}<0.001\right.$; Fig. 1).

HOXB7 protein is overexpressed in two breast cancer cells. To detect whether the protein expression level of HOXB7 was in accordance with the results of the mRNA expression level in breast cancer cells, western blotting was used in the same two human breast cancer cell lines, namely MDA-MB-231 and MCF-7 cells. The results of the western blotting revealed that $\mathrm{HOXB} 7$ protein was also overexpressed in MDA-MB-231 and MCF-7 breast cancer cell lines and the expression level in MCF-7 breast cancer cells was significantly higher compared with that in MDA-231 breast cancer cells ( ${ }^{* * *} \mathrm{P}<0.001$; Fig. 2). Therefore, combined with the result in Fig. 1, the MCF-7 human breast cancer cell line was selected for further experiments.

Detection of the optimal conditions of transfection into MCF-7 cells with HOXB7-siRNA. To optimize conditions of transfection, three different concentrations of HOXB7-siRNA-NC-CY3 (fluorescent negative control) were transfected into MCF-7 breast cancer cells. As shown in Fig. 3, 
A

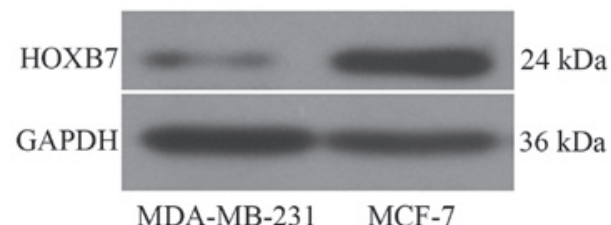

B

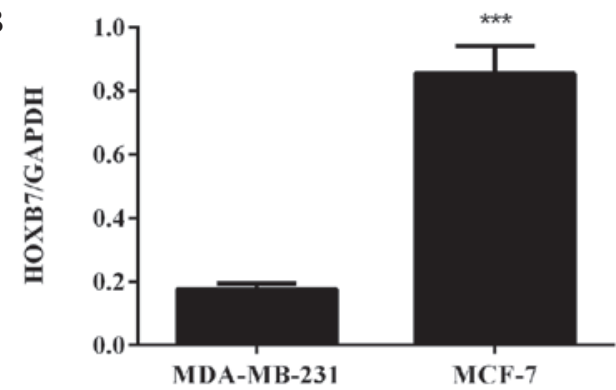

Figure 2. Protein expression level of HOXB7 in two breast cancer cell lines measured by western blotting. The optical density for target protein is shown as the proportion of GAPDH optical density. (A) HOXB7 protein is overexpressed in MDA-MB-231 and MCF-7 breast cancer cell lines and (B) the expression levels in MCF-7 breast cancer cells were significantly higher compared with that in MDA-MB-231 breast cancer cells $\left({ }^{* * *} \mathrm{P}<0.001\right)$. HOXB7, homeobox B7.

all MCF-7 cells transfected with HOXB7-siRNA for 4-6 h exhibited red fluorescence under a fluorescence microscope. It was observed that the untransfected MCF-7 exhibited no red fluorescence (Fig.3A) and the MCF-7 cells transfected with $0.1 \mu \mathrm{M}$ siRNA demonstrated a little red fluorescence (Fig. 3B). By contrast, $~ 80 \%$ infected cells exhibited red fluorescence at an siRNA concentration of $0.2 \mu \mathrm{M}$ as shown in Fig. 3C, while 90\% exhibited red fluorescence at an siRNA concentration of $0.4 \mu \mathrm{M}$ as shown in Fig. 3D, suggesting successful transfection. Thus, the concentration of $0.4 \mu \mathrm{M}$ siRNA that exhibited the highest transfection efficiency was selected for the following experiments.

HOXB7 mRNA expression level is downregulated following siRNA transfection. To determine the interference efficiency of HOXB7-siRNA on MCF-7 cells, RT-qPCR was used following transfection for $48 \mathrm{~h}$. The results demonstrated that HOXB7 mRNA was overexpressed in Con-B and Sn groups following transfection and no clear difference was observed in the two groups $(\mathrm{P}>0.05)$. However, the mRNA expression levels of HOXB7 in the S1, S2 and S3 groups were significantly downregulated compared with the Con-B and Sn groups with interference efficiencies of $63.38 \pm 0.02,81.53 \pm 0.01$ and $84.87 \pm 0.02 \%$, respectively. The differences were statistically significant $\left({ }^{* *} \mathrm{P}<0.01\right.$ and ${ }^{* * *} \mathrm{P}<0.001$; Fig. 4). The mRNA expression level of HOXB7 was the lowest in the S3 group and differed markedly from that in the Con-B and Sn groups $\left({ }^{* * * *} \mathrm{P}<0.001\right.$; Fig. 4).

HOXB7 protein expression level is downregulated following siRNA transfection. To further determine the interference efficiency of HOXB7-siRNA on MCF-7 cells, western blotting was used following transfection for $72 \mathrm{~h}$. The results demonstrated that HOXB7 protein was overexpressed in the Con-B and Sn groups following transfection and no differences were observed between the two groups $(\mathrm{P}>0.05)$. However, the expression of
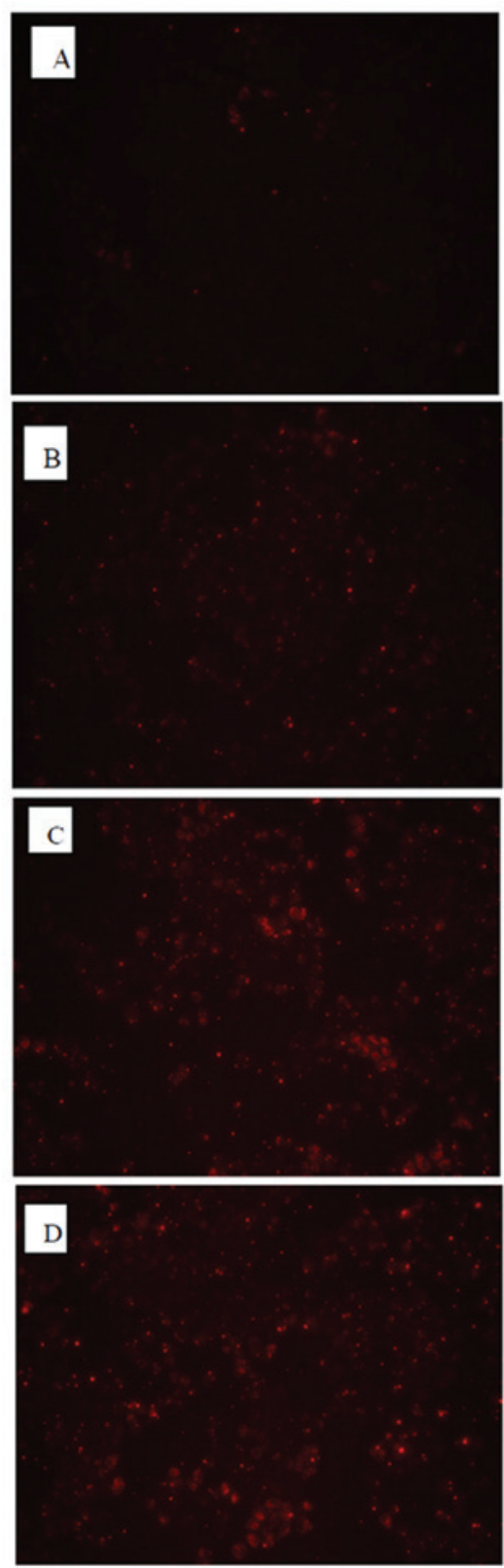

Figure 3. MCF-7 cells transfected with HOXB7-siRNA-NC-CY3 (fluorescent negative control) demonstrated red fluorescence (magnification, x100). (A) Blank controls. Cells were incubated for $4-6 \mathrm{~h}$ with (B) $0.1 \mu \mathrm{M}$ siRNA, (C) $0.2 \mu \mathrm{M}$ siRNA or (D) $0.4 \mu \mathrm{M}$ siRNA. HOXB7, homeobox B7.

HOXB7 protein in the S1, S2 and S3 groups was significantly downregulated compared with the Con-B and Sn groups with interference efficiencies of $53.88 \pm 0.0001,65.22 \pm 0.004$ and $65.25 \pm 0.001 \%$, respectively. The differences were all statistically significant $\left({ }^{* * *} \mathrm{P}<0.001\right.$; Fig. 5$)$. The HOXB7 protein expression level was the lowest in the S3 group and differed markedly from that in the Con-B and Sn groups $\left({ }^{* * *} \mathrm{P}<0.001\right.$; Fig. 5). Combined with the result in Fig. 4, S3 had the maximum inhibition efficiency of HOXB7 and therefore $\mathrm{S} 3$ was used in the following experiments.

Downregulation of HOXB7 gene expression effectively inhibits MCF-7 cell proliferation. To determine the effect of HOXB7-S3 on cell proliferation in MCF-7 breast cancer cells, a CCK-8 assay was used. As shown in Fig. 6, the 


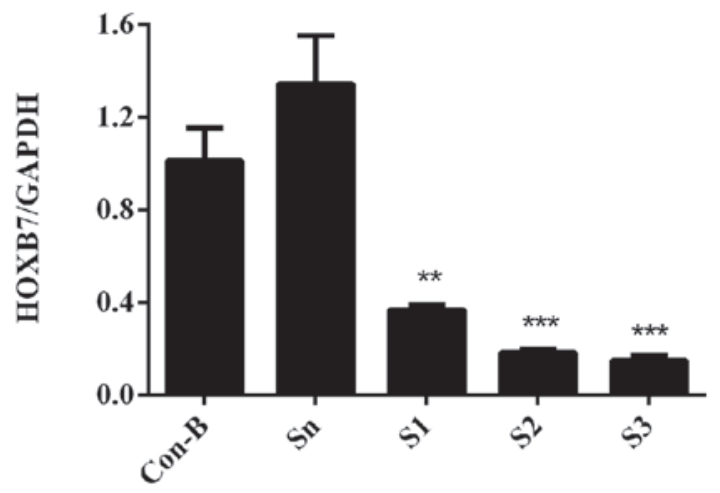

Figure 4. mRNA expression level of HOXB7 following transfection for $48 \mathrm{~h}$. Con-B group, blank control group; Sn group, negative control siRNA; S1 group, S1 transfection group; S2 group, S2 transfection group and S3 group, S3 transfection group. Cells in the S3 group had the lowest HOXB7 mRNA expression level $\left({ }^{* * *} \mathrm{P}<0.001\right)$. HOXB7, homeobox B7.
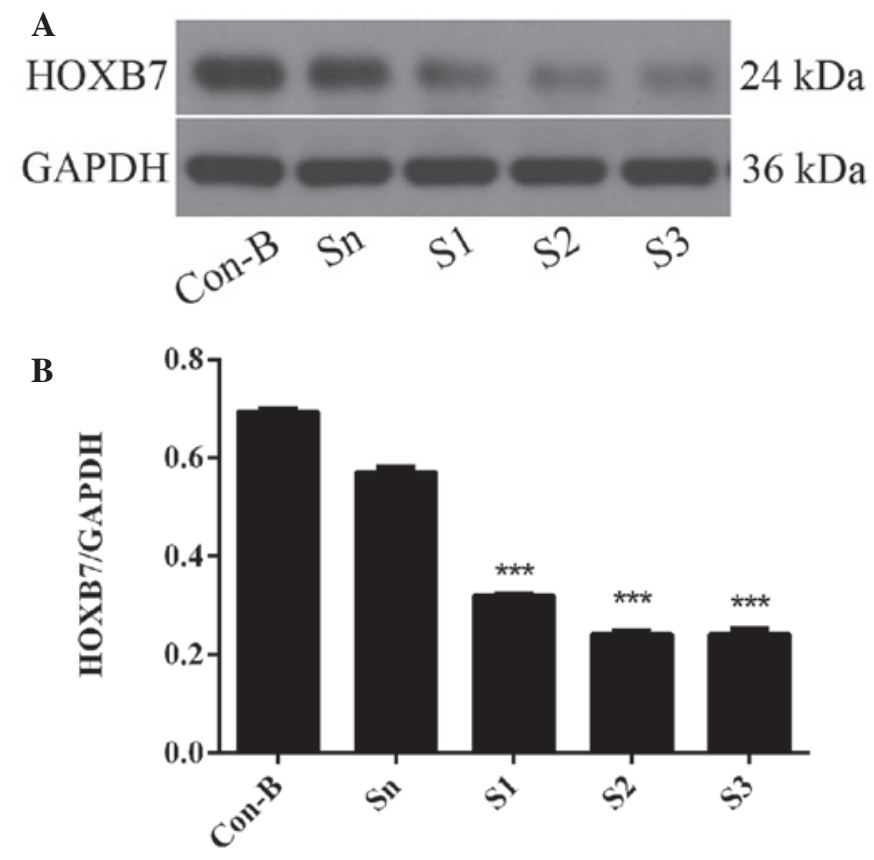

Figure 5. Protein expression of HOXB7 following transfection for $72 \mathrm{~h}$ : Con-B group, blank control group; Sn group, negative control siRNA; S1 group, S1 transfection group; S2 group, S2 transfection group and S3 group, S3 transfection group. (A) The protein expression level of HOXB7 was measured by western blotting. (B) The optical density for target protein is shown as a proportion of GAPDH optical density. Cells in the S3 group had the lowest HOXB7 protein expression level $\left({ }^{* * *} \mathrm{P}<0.001\right.$, compared with the Con B and Sn groups). HOXB7, homeobox B7.

cell viability of the three groups demonstrated no significant difference following transfection with HOXB7-S3 or HOXB7-Sn for $24 \mathrm{~h}$. Between 48 and $72 \mathrm{~h}$, the cell viability of the $\mathrm{S} 3$ group was significantly decreased compared with that of the Con-B groups. In particular, the cell viability of the $\mathrm{S} 3$ group $(74.43 \pm 2.55 \%)$ at $48 \mathrm{~h}$ post-transfection was significantly decreased compared with that of the Con-B group $(111.97 \pm 3.66 \%)$ and $\mathrm{Sn}$ group $(100 \pm 1.58 \%)$. The difference was statistically significant $\left({ }^{* * *} \mathrm{P}<0.001\right)$. The cell viability of the S3 group at $96 \mathrm{~h}$ post-transfection demonstrated a partially decreased cell survival, however, this decease was not so pronounced. This result demonstrated that HOXB7-S3 could

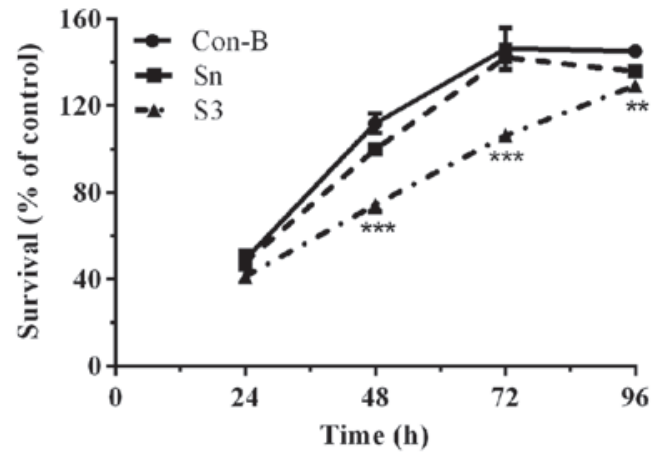

Figure 6. CCK-8 test of cell proliferation. Con-B group, blank control group; Sn group, negative control siRNA; S3 group, S3 transfection group. The CCK- 8 test demonstrated that the cell viability of the $\mathrm{S} 3$ group was significantly decreased compared with the other two groups between 48 and $72 \mathrm{~h}$ and the difference was statistically significant $\left({ }^{* * *} \mathrm{P}<0.001\right)$. Data are presented as the average of three independent experiments each containing five replicates. CCK-8, cell counting kit-8; siRNA, small interfering RNA.

effectively and significantly inhibit the proliferation of human breast cancer MCF-7 cells.

Downregulation of HOXB7 gene expression effectively enhances MCF-7 cell apoptosis. To detect whether the effect of HOXB7-S3 on cell proliferation in MCF-7 breast cancer cells occurred by apoptosis, the percentage of early-stage apoptotic cells and late-stage apoptotic cells was measured in three groups by FCM. At $48 \mathrm{~h}$ post-transfection of siRNA, the total number of apoptotic cells $(12.70 \pm 1.75 \%)$ was markedly increased in the S3 group, compared with $7.83 \pm 0.47 \%$ in the Con-B group and $6.46 \pm 0.49 \%$ in the $\mathrm{Sn}$ group, respectively (Fig. 7). The differences between the three groups were statistically significant $\left({ }^{* *} \mathrm{P}<0.01\right)$. These results indicated that HOXB7-S3 enhanced MCF-7 cell apoptosis.

Downregulation of HOXB7 gene expression inhibits MCF-7 cell invasion. To determine the effect of HOXB7-S3 on cell proliferation in MCF-7 breast cancer cells, the number of cells that had migrated through the Matrigel membrane was measured at 24 and $48 \mathrm{~h}$ post-transfection of MCF-7 cells with HOXB7-S3 by Transwell assay. As shown in Fig. 8A and B, the number of migrated cells in the $\mathrm{S} 3$ group was markedly reduced compared with in the Sn and Con-B groups. The number of migrated cells in the S3, Con-B and Sn groups $24 \mathrm{~h}$ post-transfection was $31 \pm 3.63,46 \pm 1.87$ and $47 \pm 2.27$, respectively. The difference was statistically significant $\left({ }^{* *} \mathrm{P}<0.01\right.$; Fig. $\left.8 \mathrm{C}\right)$. At $48 \mathrm{~h}$ post-transfection, the number of migrated cells in the S3 group was $75 \pm 3.49$, which was apparently reduced compared with $125 \pm 7.18$ in the Con-B group and $121 \pm 3.25$ in the Sn group (Fig. 8B). The difference was statistically significant $\left({ }^{* * *} \mathrm{P}<0.001\right.$; Fig. $\left.8 \mathrm{D}\right)$. This suggested that HOXB7-S3 markedly inhibited the invasiveness of MCF-7 cells.

\section{Discussion}

Breast cancer is characterized by a multiphasic process in which a series of changes occur in sequence, leading to the loss of control of cell proliferation, differentiation, apoptosis and 


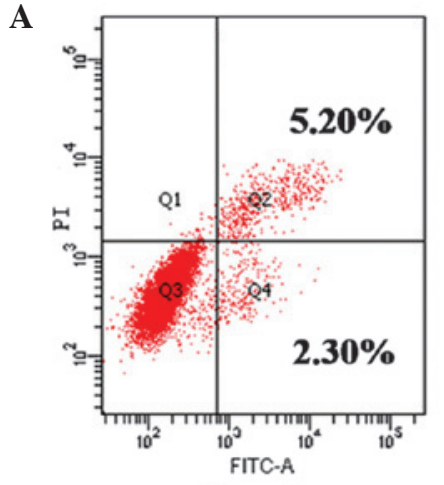

Con-B

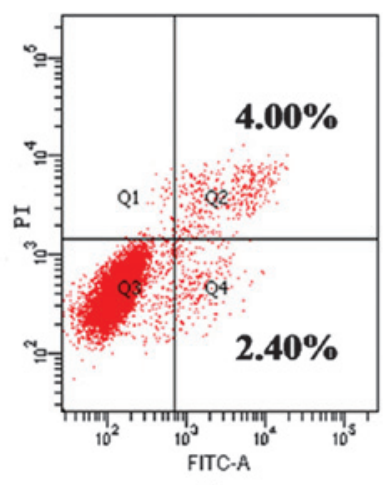

Sn

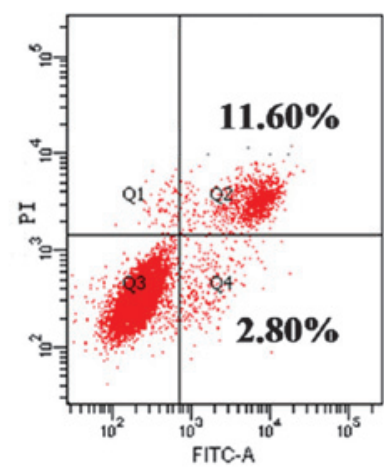

S3

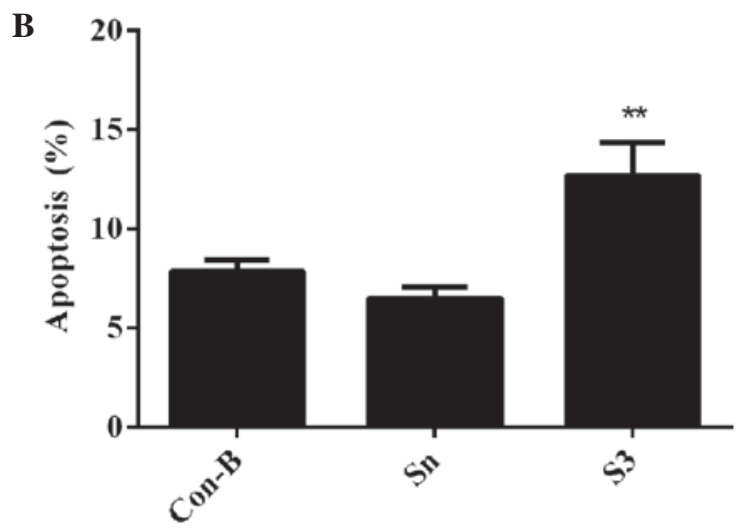

Figure 7. Apoptotic rate following transfection for $48 \mathrm{~h}$ in MCF-7 cells. Con-B group, blank control group; Sn group, negative control siRNA; S3 group, S3 transfection group. The apoptotic rate in S3 groups was the highest compared with that in Con-B groups and Sn groups (** $\mathrm{P}<0.01$ ). (A) Early apoptotic cells are defined as Annexin $\mathrm{V}^{+} / \mathrm{PI}^{-}$, whereas late apoptotic cells are Annexin $\mathrm{V}^{+} / \mathrm{PI}^{+}$. Data are representative results for one of the three replicates. (B) Percentage of Annexin $\mathrm{V}^{+} / \mathrm{PI}^{-} \mathrm{MCF}-7$ cells following transfection with $\mathrm{S} 3$ for $48 \mathrm{~h}$. HOXB7-S3 effectively enhanced MCF-7 cell apoptosis. Data are the average of three independent experiments each containing three replicates. HOXB7, homeobox B7; PI, propidium iodide; siRNA, small interfering RNA.

DNA repair (19). To date, there have been numerous studies demonstrating a possible association between the abnormal expression of HOX genes and breast cancer. For example, Ramen et al and Chu et al found that HOXA5 and HOXA10 are underexpressed in breast cancer $(20,21)$. Conversely, Jansen et al suggested that HOXB13 is overexpressed in breast cancer $(22,23)$.

Initially identified in Drosophila (24), the HOX genes encode a family of highly conserved transcription factors that normally regulate temporospatial development of the extremities and organs (25). Aberrant expression of these genes in different tissues has been demonstrated to be associated with tumorigenesis $(26,27)$, particularly HOXB7, a member of the $H O X$ gene family, which is reported to be overexpressed in numerous cancer cells, including melanoma cells, ovarian epithelial cells and $\mathrm{SkBr} 3$ breast carcinoma cells $(15,28,29)$ has a key role in tumorigenesis. To the best of our knowledge, the current study is the first to demonstrate that the mRNA and protein expression of HOXB7 was overexpressed in MDA-MB-231 and MCF-7 breast cancer cell lines.

Additionally, it was reported that as a transcription factor, HOXB7 has two opposite functions in different cellular contexts. The majority of studies supported that HOXB7 may be important in promoting the multistep process of tumor formation and progression, including transformation, proliferation, survival, angiogenesis, invasion and metastasis $(12,14,17,30,31)$. By contrast, another study observed a promoting role of $\mathrm{HOXB7}$ in differentiation in hematopoietic stem cells and multipotent mesenchymal cells (32). In order to investigate the role $\mathrm{HOXB} 7$ in breast cancer cells, three pairs of HOXB7-siRNA were transfected into MCF-7 breast cancer cells and the mRNA and protein expression levels of HOXB7 were effectively downregulated. In particular, HOXB7-S3 significantly and specifically inhibited HOXB7 expression at the mRNA and protein levels with interference efficiencies of $84.87 \pm 0.02$ and $65.25 \pm 0.001 \%$, respectively. Thus, it was concluded that HOXB7-S3 could effectively induce gene RNA interference (RNAi) and HOXB7-S3 was selected to downregulate HOXB7 gene expression in the following experiments. The results of the CCK-8 assay and transwell chambers demonstrated that downregulation of $\mathrm{HOXB} 7$ gene expression effectively inhibited MCF-7 cell proliferation and invasion in MCF-7 cells, which contributed to malignant transformation and tumorigenesis. The present data predominantly support the pro-tumorigenic function of HOXB7. In addition, understanding the molecular abnormalities of HOXB7 involved in the pathogenesis of breast cancer cells may reveal new targets for therapy and HOXB7-siRNA and antagonists could be used to inhibit the proliferation and invasion capacity of breast cancer cells.

Although HOXB7 has been associated with the regulation of proliferation and invasion of cancer cells, the molecular mechanisms remain poorly identified. Certain studies reported that bFGF, one of the direct targets of HOXB7, 
A

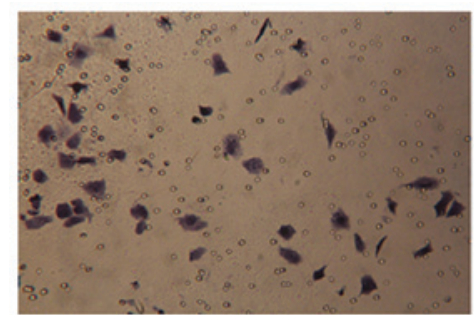

Con-B

B

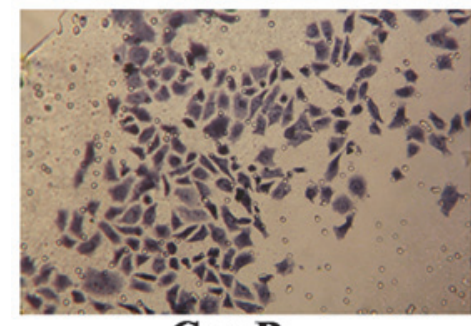

Con-B

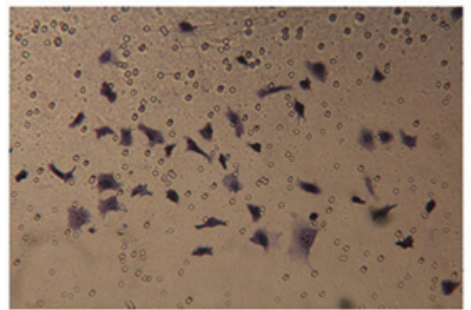

Sn

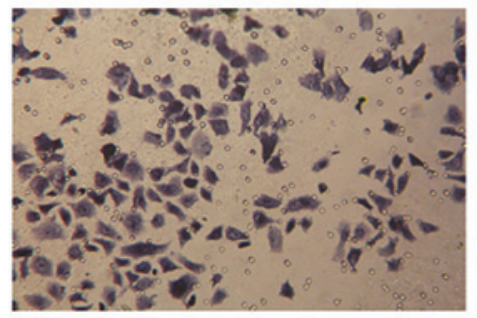

Sn

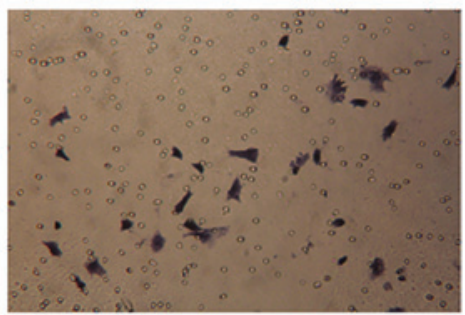

S3

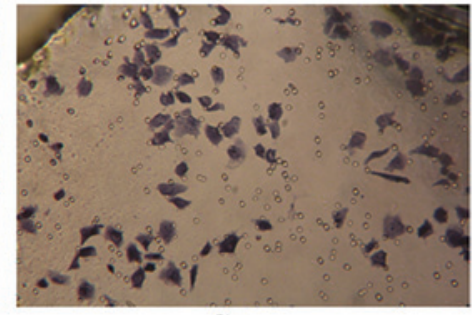

S3

C

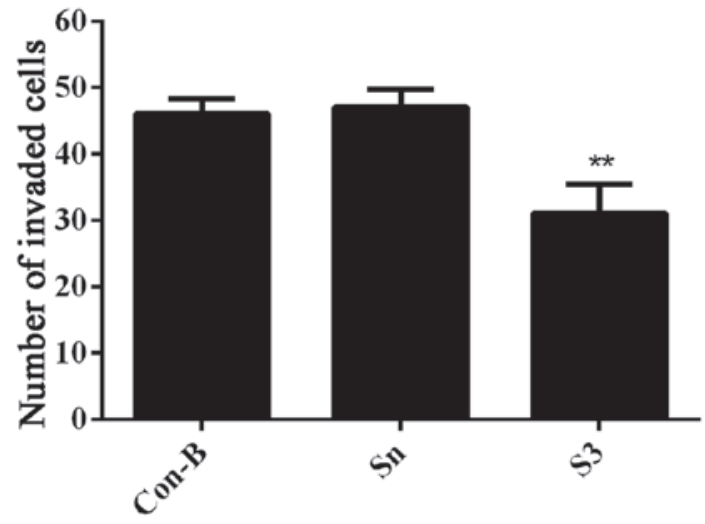

D

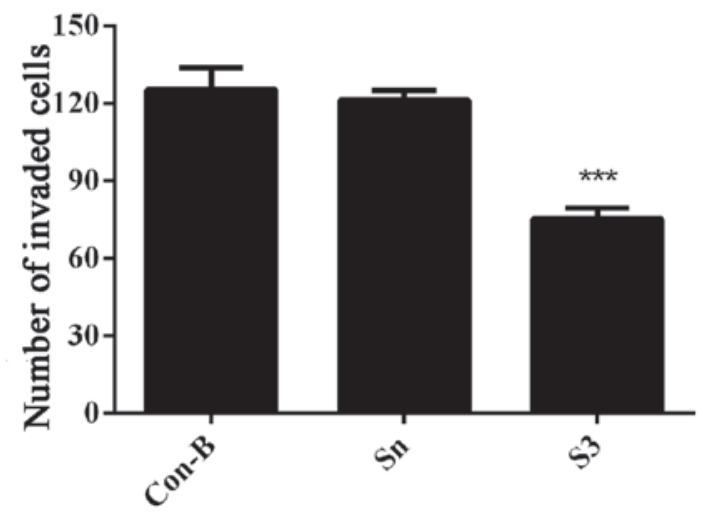

Figure 8. HOXB7-S3 inhibits MCF-7 cell invasion. Con-B group, blank control group; Sn group, negative control siRNA; S3 group, S3 transfection group. siRNA was transfected into MCF-7 cells for (A) 24 and (B) $48 \mathrm{~h}$ for the invasion assay. The number of migrated cells was significantly lower in the S3 group compared with in the Con-B group and Sn group at $(\mathrm{C}) 24\left({ }^{* *} \mathrm{P}<0.01\right)$ and $(\mathrm{D}) 48 \mathrm{~h}\left({ }^{* * *} \mathrm{P}<0.001\right)$. Data are the average of three independent experiments each containing three replicates. HOXB7, homeobox B7.

contributed to HOXB7-induced cellular proliferation and transformation $(14,15)$. In addition to bFGF, Carè et al found that HOXB7 can also induce the expression of other genes, particularly those associated with angiogenesis and tumor invasion, including vascular endothelial growth factor, interleukin-8, angiopoietin-2 and metalloproteases 2 and 9 (31). Wu et al demonstrated that HOXB7 could activate the Ras-RAF-MAPK pathway in breast cancer cell lines, thereby promoting cell proliferation (16). In the current study, whether the effect of HOXB7-S3 on cell proliferation in MCF-7 breast cancer cells occurred by apoptosis was detected using FCM and the results demonstrated that at $48 \mathrm{~h}$ post-transfection of siRNA, the total number of apoptotic cells $(12.70 \pm 1.75 \%)$ was markedly increased in the $\mathrm{S} 3$ group, compared with $7.83 \pm 0.47 \%$ in the Con-B groups and $6.46 \pm 0.49 \%$ in the Sn groups, respectively (Fig. 7), which was in accordance with the result of the CCK-8 assay demonstrating that the cell viability of the $\mathrm{S} 3$ groups $(74.43 \pm 2.55 \%)$ at $48 \mathrm{~h}$ post-transfection was significantly decreased compared with that of the Con-B groups $(111.97 \pm 3.66 \%)$ and Sn groups $(100 \pm 1.58 \%$; Fig. 6$)$, which indicated that HOXB7-S3 may 
inhibit the proliferation of MCF-7 breast cancer cells through enhancing the apoptotic rate.

In conclusion, the results of the present study demonstrated that HOXB7-S3 decreased the mRNA and protein expression levels of HOXB7 and inhibited the cell proliferation and invasion of MCF-7 breast cancer cells, indicating that HOXB7 RNAi is a potential treatment for breast cancer. HOXB7 may be a potential and valuable therapeutic target in human breast cancer.

\section{Acknowledgements}

This study was supported by grants from the Science and Technology of Hubei Province Funds (no. 2011 CHB 020[SP1]). The authors would like to thank all members of our laboratories for their technical assistance and advice during the experiments.

\section{References}

1. Jemal A, Bray F, Center MM, Ferlay J, Ward E and Forman D: Global cancer statistics. CA Cancer J Clin 61: 69-90, 2011.

2. Walsh T, Casadei S, Coats KH, Swisher E, Stray SM, Higgins J, Roach KC, Mandell J, Lee MK, Ciernikova S, et al: Spectrum of mutations in BRCA1, BRCA2, CHEK2 and TP53 in families at high risk of breast cancer. JAMA 295: 1379-1388, 2006.

3. Mantzourani M, Gogas H, Katsandris A and Meletis J: Severe thrombocytopenia related to trastuzumab infusion. Med Sci Monit 17: CS85-CS87, 2011.

4. Nunes FD, de Almeida FC, Tucci R and de Sousa SC: Homeobox genes: A molecular link between development and cancer. Pesqui Odontol Bras 17: 94-98, 2003.

5. Grier DG, Thompson A, Kwasniewska A, McGonigle GJ, Halliday HL and Lappin TR: The pathophysiology of HOX genes and their role in cancer. J Pathol 205: 154-171, 2005.

6. Bhatlekar S, Fields JZ and Boman BM: HOX genes and their role in the development of human cancers. J Mol Med (Berl) 92: 811-823, 2014

7. Nguyen Kovochich A, Arensman M, Lay AR, Rao NP, Donahue T, Li X, French SW and Dawson DW: HOXB7 promotes invasion and predicts survival in pancreatic adenocarcinoma. Cancer 119: 529-539, 2013

8. Cantile M, Pettinato G, Procino A, Feliciello I, Cindolo L and Cillo C: In vivo expression of the whole HOX gene network in human breast cancer. Eur J Cancer 39: 257-264, 2003.

9. McGinnis W and Krumlauf R: Homeobox genes and axial patterning. Cell 68: 283-302, 1992.

10. Pineault N, Abramovich $\mathrm{C}$, Ohta $\mathrm{H}$ and Humphries $\mathrm{RK}$ : Differential and common leukemogenic potentials of multiple NUP98-Hox fusion proteins alone or with Meis1. Mol Cell Biol 24: 1907-1917, 2004

11. Hong JH, Lee JK, Park JJ, Lee NW, Lee KW and Na JY: Expression pattern of the class I homeobox genes in ovarian carcinoma. J Gynecol Oncol 21: 29-37, 2010.

12. Chile T, Fortes MA, Corrêa-Giannella ML, Brentani HP, Maria DA, Puga RD, de Paula Vde J, Kubrusly MS, Novak EM, Bacchella T, et al: HOXB7 mRNA is overexpressed in pancreatic ductal adenocarcinomas and its knockdown induces cell cycle arrest and apoptosis. BMC Cancer 13: 451, 2013.

13. Chen KN, Gu ZD, Ke Y, Li JY, Shi XT and Xu GW: Expression of $11 \mathrm{HOX}$ genes is deregulated in esophageal squamous cell carcinoma. Clin Cancer Res 11: 1044-1049, 2005.

14. De Souza Setubal Destro MF, Bitu CC, Zecchin KG, Graner E, Lopes MA, Kowalski LP and Coletta RD: Overexpression of HOXB7 homeobox gene in oral cancer induces cellular proliferation and is associated with poor prognosis. Int $\mathrm{J}$ Oncol 36: 141-149, 2010.
15. Naora H, Yang YQ, Montz FJ, Seidman JD, Kurman RJ and Roden RB: A serologically identified tumor antigen encoded by a homeobox gene promotes growth of ovarian epithelial cells. Proc Natl Acad Sci USA 98: 4060-4065, 2001

16. Wu X, Chen H, Parker B, Rubin E, Zhu T, Lee JS, Argani P and Sukumar S: HOXB7, a homeodomain protein, is overexpressed in breast cancer and confers epithelial-mesenchymal transition. Cancer Res 66: 9527-9534, 2006.

17. Chen H, Lee JS, Liang X, Zhang H, Zhu T, Zhang Z, Taylor ME, Zahnow C, Feigenbaum L, Rein A, et al: Hoxb7 inhibits transgenic HER-2/neu-induced mouse mammary tumor onset but promotes progression and lung metastasis. Cancer Res 68: 3637-3644, 2008

18. Livak KJ and Schmittgen TD: Analysis of relative gene expression data using real-time quantitative PCR and the 2(-Delta Delta C(T)). Methods 25: 402-408, 2001.

19. Vogelstein B and Kinzler KW: The multistep nature of cancer. Trends Genet 9: 138-141, 1993.

20. Raman V, Martensen SA, Reisman D, Evron E, Odenwald WF, Jaffee E, Marks J and Sukumar S: Compromised HOXA5 function can limit p53 expression in human breast tumours. Nature 405: 974-978, 2000.

21. Chu MC, Selam FB and Taylor HS: HOXA10 regulates p53 expression and matrigel invasion in human breast cancer cells. Cancer Biol Ther 3: 568-572, 2004.

22. Jansen MP, Sieuwerts AM, Look MP, Ritstier K, Meijer-van Gelder ME, van Staveren IL, Klijn JG, Foekens JA and Berns EM: HOXB13-to-IL17BR expression ratio is related with tumor aggressiveness and response to tamoxifen of recurrent breast cancer: A retrospective study. J Clin Oncol 25: 662-668, 2007.

23. Shah N, Jin K, Cruz LA, Park S, Sadik H, Cho S, Goswami CP, Nakshatri H, Gupta R, Chang HY, et al: HOXB13 mediates tamoxifen resistance and invasiveness in human breast cancer by suppressing ER $\alpha$ and inducing IL-6 expression. Cancer Res 73: 5449-5458, 2013.

24. Krumlauf R: Hox genes in vertebrate development. Cell 78: 191-201, 1994

25. Garaulet DL, Castellanos MC, Bejarano F, Sanfilippo P, Tyler DM, Allan DW, Sánchez-Herrero E and Lai EC: Homeotic function of Drosophila Bithorax-complex miRNAs mediates fertility by restricting multiple Hox genes and TALE cofactors in the CNS. Dev Cell 29: 635-648, 2014.

26. Bhatlekar S, Addya S, Salunek M, Orr CR, Surrey S, McKenzie S, Fields JZ and Boman BM: Identification of a developmental gene expression signature, including HOX genes, for the normal human colonic crypt stem cell niche: Overexpression of the signature parallels stem cell overpopulation during colon tumorigenesis. Stem Cells Dev 23: 167-179, 2014.

27. Cantile M, Scognamiglio G, La Sala L, La Mantia E, Scaramuzza V, Valentino E, Tatangelo F, Losito S, Pezzullo L, Chiofalo MG, et al: Aberrant expression of posterior HOX genes in well differentiated histotypes of thyroid cancers. Int J Mol Sci 14: 21727-21740, 2013

28. Caré A, Silvani A, Meccia E, Mattia G, Stoppacciaro A, Parmiani G, Peschle C and Colombo MP: HOXB7 constitutively activates basic fibroblast growth factor in melanomas. Mol Cell Biol 16: 4842-4851, 1996.

29. Caré A, Silvani A, Meccia E, Mattia G, Peschle C and Colombo MP: Transduction of the SkBr3 breast carcinoma cell line with the HOXB7 gene induces bFGF expression, increases cell proliferation and reduces growth factor dependence. Oncogene 16: 3285-3289, 1998.

30. Liao WT, Jiang D, Yuan J, Cui YM, Shi XW, Chen CM, Bian XW, Deng YJ and Ding YQ: HOXB7 as a prognostic factor and mediator of colorectal cancer progression. Clin Cancer Res 17: 3569-3578, 2011

31. Carè A, Felicetti F, Meccia E, Bottero L, Parenza M, Stoppacciaro A, Peschle C and Colombo MP: HOXB7: A key factor for tumor-associated angiogenic switch. Cancer Res 61: 6532-6539, 2001.

32. Boström K, Tintut Y, Kao SC, Stanford WP and Demer LL: HOXB7 overexpression promotes differentiation of C3H10T1/2 cells to smooth muscle cells. J Cell Biochem 78: 210-221, 2000. 